https://doi.org/10.37208/tgn27219

\section{A re-assessment and review of some published amphibian and reptile records in the Clyde area, Scotland}

\author{
C.J. McInerny ${ }^{+}$, E. Paterson*, R.B. Weddle ${ }^{\#} \&$ \\ J.R. Downie ${ }^{\dagger}$
}

+School of Life Sciences, Davidson Building, University of Glasgow, Glasgow G12 8QQ

*56 Lochranza Drive, East Kilbride G75 9NA

\#89 Novar Drive, Glasgow G12 9SS

${ }^{\dagger}$ School of Life Sciences, Graham Kerr Building, University of Glasgow, Glasgow G12 8QQ

E-mail: chris.mcinerny@ glasgow.ac.uk

A number of compilations of herptile (amphibian and reptile) records pertaining to the Clyde area, Scotland created by Dr J.A. Gibson were published in The Western Naturalist and The Scottish Naturalist during the 1980s and 1990s (e.g. Gibson, 1998; Gibson, 2003; and references cited therein). Dr Gibson edited and published both periodicals at the time. The herptile records that these publications contained were subsequently digitised for the Biological Records Centre (BRC) at Monkswood, Cambridgeshire, England and added to their database (H. Arnold, pers. comm.), whence they were submitted to the National Biodiversity Network (NBN; https://nbn.org.uk/) when it was created. The BRC records were also made available to Glasgow Museums Biological Records Centre (GMBRC), where doubts arose about their reliability, particularly those derived from the $10 \mathrm{~km}$ distribution maps in some of the publications.

Because of these doubts a need to review the herptile records in the national databases was discussed repeatedly at meetings of the Council of the Glasgow Natural History Society (GNHS) and the Clyde Amphibian and Reptile Group (CARG). This culminated in a determination to re-assess the records. To do this an application was submitted to the Blodwen Lloyd Binns Bequest Fund of GNHS for funding to underwrite costs incurred during the review process, which was successful.

Independently, the records were explicitly excluded from The Amphibians and Reptiles of Scotland (McInerny \& Minting, 2016), with the reasons for this described in the bibliography where two Gibson publications were listed.

The BRC data are now managed by the Centre for Ecology and Hydrology (CEH), Wallingford, Oxford, England. The Gibson sourced records have new reference numbers, and so a new copy of the data was obtained so that appropriate feedback, including the assessment of the individual records, could be provided to $\mathrm{CEH}$ at the conclusion of this review process.

Initially a list of Gibson publications was collated using the primary literature and other cited papers in the GNHS Library (Gibson, 1998; Gibson, 2003; and references cited therein). This allowed the interrogation of online resources such as the Biodiversity Heritage Library (https://www.biodiversitylibrary.org), and the National Library of Scotland to allow copies of publications to be sourced and reviewed. From these publications records were extracted and, where possible, the source of the records was noted. Source publications were accessed by the same means, for verification purposes.

The herptile records were considered and reviewed following a consistent and objective procedure:

1. Records were accepted and retained where a source could be independently verified.

2. Record sources that were not from a Gibson publication were accepted and retained, even if they could not be independently verified.

3. Records sourced directly from a Gibson publication were considered not verifiable if they lacked information to confirm validity. Such information included: a detailed grid reference, date of record, name of original recorder, number of specimens, or accompanying notes and photographs. Such records were rejected.

All records were then assessed against the NBN Gateway criteria for record validity and verification, prior to submission to the GMBRC for further verification and appropriate amendment of the same records in the GMBRC database. These amended records can be accessed by enquiries to the GMBRC (https://www.glasgowlife.org.uk/museums/biologicalrecord-centre).

The unverified rejected records will be retained in the GMBRC database, though marked "considered incorrect" to prevent such records from being reproduced in future reports and publications. Importantly, this procedure also provides an "audit trail" for future reference, and is therefore preferable to deleting the records entirely. This information, along with this publication, will be forwarded to $\mathrm{CEH}$ so that they can treat the same records similarly and update the NBN Atlas appropriately.

This short note describes an approach to re-assess a number of herptile records in the Clyde area sourced from Gibson publications. A large number of these have been found to be un-verifiable and so have been removed from natural history databases. This results in databases of credible and verified herptile records for the Clyde area. 
Comparable issues with similar sourced records are found in databases for other area of Scotland, for example Argyll (Lorne Natural History Group), where we suggest a related approach should be adopted and implemented.

Thanks are due to Henry Arnold (Monkswood) for the original records digitised by $\mathrm{BRC}$; and to Stephanie Rorke (Wallingford), CEH Database Manager, for the CEH copy of the data, and for implementing our recommendations. We are grateful to the Administrators of the Blodwen Lloyd Binns Bequest Fund for a grant to support the review process.

\section{REFERENCES}

Gibson, J.A. (1998). A Regional Bibliography of the Reptiles and Amphibians of the West of Scotland (Clyde Faunal Area). Scottish Natural History Library.

Gibson, J.A. (2003). The reptiles and amphibians of the Clyde area: a twenty-year update, 1982-2002. The Scottish Naturalist 115, 93-111. https://www.biodiversitylibrary.org/item/214260\#p age/33/mode/1up

McInerny, C.J. \& Minting, P. (2016). The Amphibians and Reptiles of Scotland. The Glasgow Natural History Society, Glasgow. https://www.glasgownaturalhistory.org.uk/books.ht $\mathrm{ml}$ 